\title{
30. DECORATED VESICLES IN BASALTIC GLASSES FROM HOLE 396, DRILLED ON LEG 45, DEEP SEA DRILLING PROJECT
}

\author{
G. Propach, Mineralogisch-Petrographisches Institut der Universität München, 8 Münich, F.R.G.
}

\begin{abstract}
The arrangement of sulfide spherules in basaltic glasses from DSDP Hole 396 is described. An increase in the diameters and spacing of the spherules corresponds to an increase in the distance of the vesicules from the pillow rim. Variations in the slopes of regression lines in plots of these data reflect different cooling rates. The amount of sulfide present in the vesicles depends on the volume of the vesicles and not on their surface areas. There is petrographic evidence that the spherules were droplets of sulfide liquid, but later growth of crystalline sulfide cannot be excluded. Formation of the sulfide was by reaction of sulfur in the gas phase with metal ions from the silicate melt. This process requires rapid diffusion of copper and nickel through the melt. Equilibrium compositions were not attained. The gas phase in the vesicles contained about 3 per cent sulfur.
\end{abstract}

\section{INTRODUCTION}

Basaltic glasses from the deep sea frequently contain decorated vesicles. These are vesicles dotted by regularly arranged sulfide spherules. This study describes vesicles of this type occurring in basaltic glasses of Hole 396, Leg 45 .

\section{VESICLE SURFACE}

The surface structures show considerable differences. Some are remarkably smooth, but high magnification shows grooves (Figures 1 through 3). Other vesicle walls appear to be porous ("microvesicular," Yeats and Mathez, 1976). Nearly identical surface features of spherules (Figures 4 and 5) and cracks in the walls of several vesicles of this type (Figure 6) suggest corrosion as the cause of this structure.

\section{SHAPE AND ARRANGEMENT OF THE SPHERULES}

In most spherules the size population is bimodal (Figures 2 and 7). Scanning electron micrographs reveal that in neither population do perfectly spherical spherules exist. The gross shape-if not altered by corrosion-is angular, and resembles crystals. This feature is more distinct with the small spherules (Figures 1 and 2). Broken-off spherules leave hemispherical pits (Figures 1 and 8 ). Within these pits are visible smaller pits which do not appear to be casts of sulfide crystals (Figure 8).

Generally, the spherules in a single vesicle are spaced uniformly with respect to each other (Figure 7). Between the larger spherules, the vesicle walls are dotted with a population of smaller spherules in a similar arrangement (Figures 2 and 7). Halos of variable width appear around the larger spherules, but not the smaller ones. Sometimes a different arrangement can be observed. In two out of seven thin sections, the spherules are preferentially concentrated on one side of the vesicle (Figures 4 and 9). In these thin sections, the distances between the spherules on the opposing sides can differ by a factor of up to 10 .

\section{RELATIONS BETWEEN SIZE AND ARRANGEMENT OF THE SPHERULES, DISTANCE FROM THE CONTACT, AND AMOUNT OF SULFIDE IN THE SPHERULES}

The radii of the vesicles themselves do not correlate with their distance from the pillow rims. The radii of the spherules and their spacing in the vesicles, however, clearly increase with growing distance from the contact (Figure 10[a-e]). (The slopes of the regression lines in Figure 10 cannot be compared rigorously. The thin sections corresponding to Figure $10(\mathrm{a}-\mathrm{c})$, are sections approximately vertical to the contact. The orientation of the thin sections to Figure 10(d) and (e), is unknown, but a similar relationship can be assumed.)

From the radii and average separation of the spherules, a mean sulfide layer thickness for each vesicle can be calculated. Because of errors in measurement, the individual figures show considerable scatter (solid squares in Figure 10). "Ideal" values of thickness, calculated from the regression lines for radius and spacing of the spherules, are indicated by broken lines in Figure 10. Obviously, the thickness of the sulfide layer may increase (Moore and Calk, 1971) or remain constant with increasing distance from the contact. The increase in the calculated thickness toward smaller diameters in Figure 10, (a) and (c), is probably caused by a systematic error in measurement. 


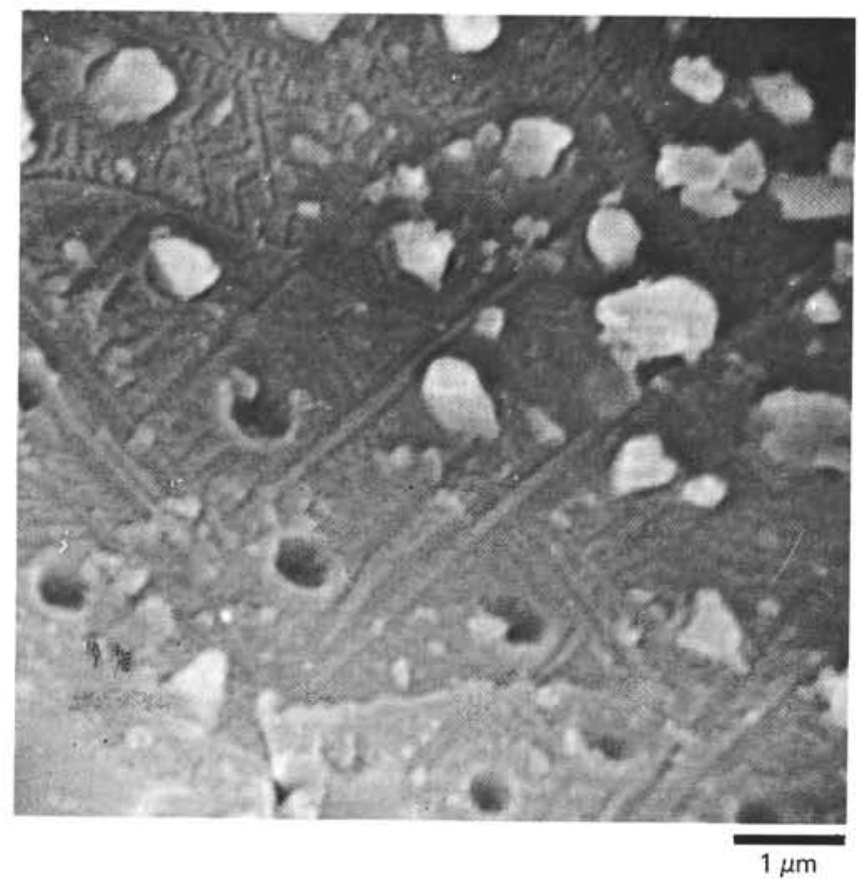

Figure 1. Angular spherules of the smaller sized population sit in hemispherical pits. The vesicle wall is dissected by grooves. SEM photo of Sample 15-1, 120-125 cm.

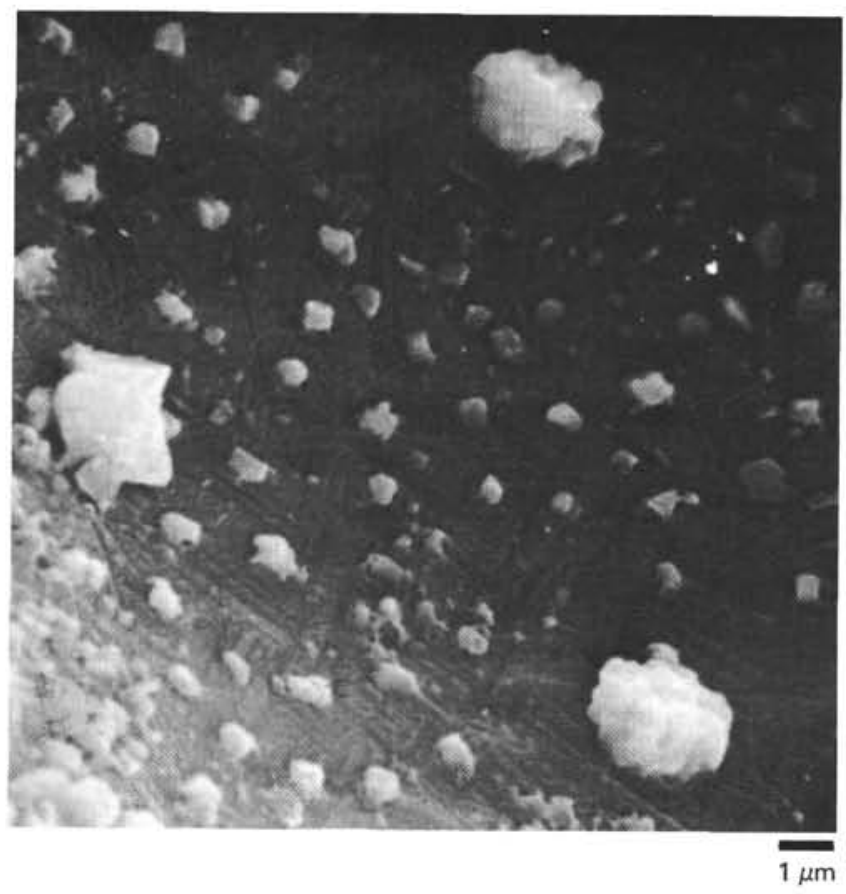

Figure 2. Three large spherules and several small ones. Note the angular shape of both types of spherules. SEM photo of Sample 15-1, 120-125 cm.

Figure 11 reveals a positive correlation between the radii of vesicles and the calculated thicknesses of sulfide layers.

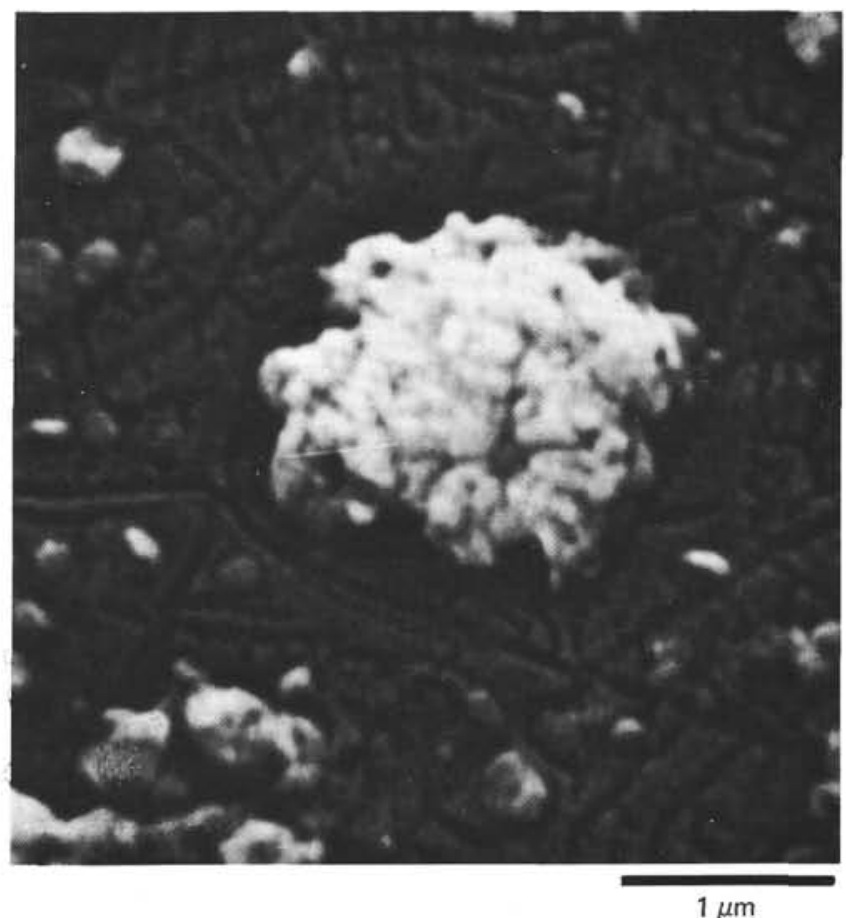

Figure 3. Large spherule with a brain-like surface structure. All the grooves in the vesicle wall are interconnected, but blind endings are frequent. The ruling principle for the distribution of grooves is equal coverage of the wall. SEM photo of Sample 15-1, 120-125 cm.

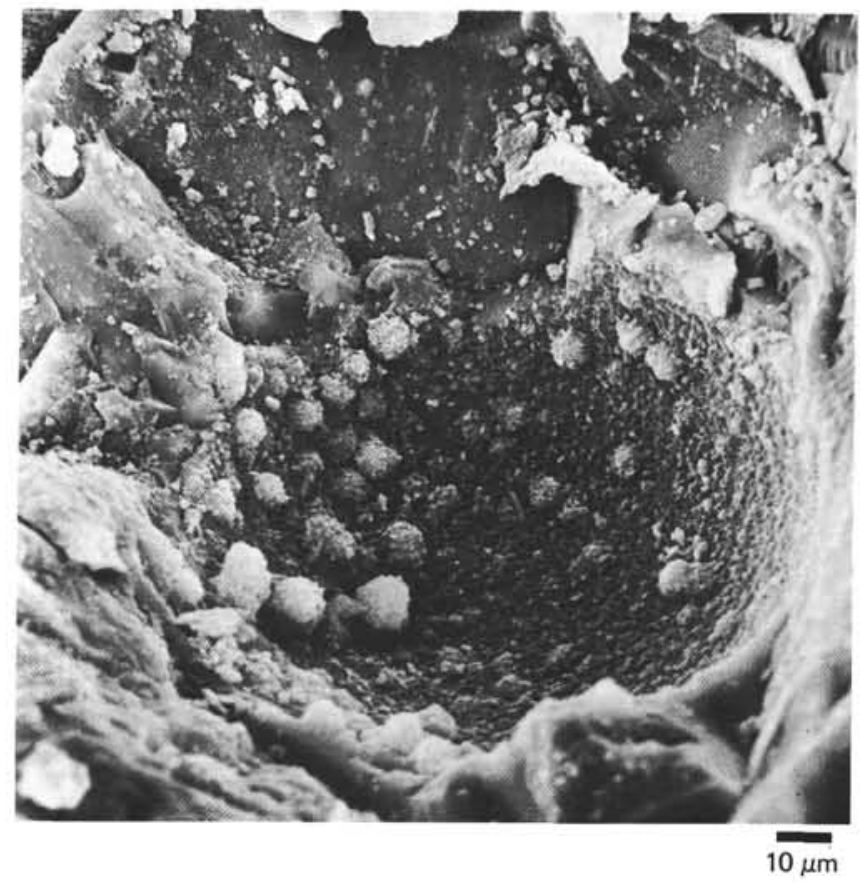

Figure 4. Part of vesicle, with spherules concentrated on the left side. Three spherules (lower left) are noticeably larger than the others. The vesicle wall and the spherules are corroded. SEM photo of Sample 15-1, 120-125 cm. 


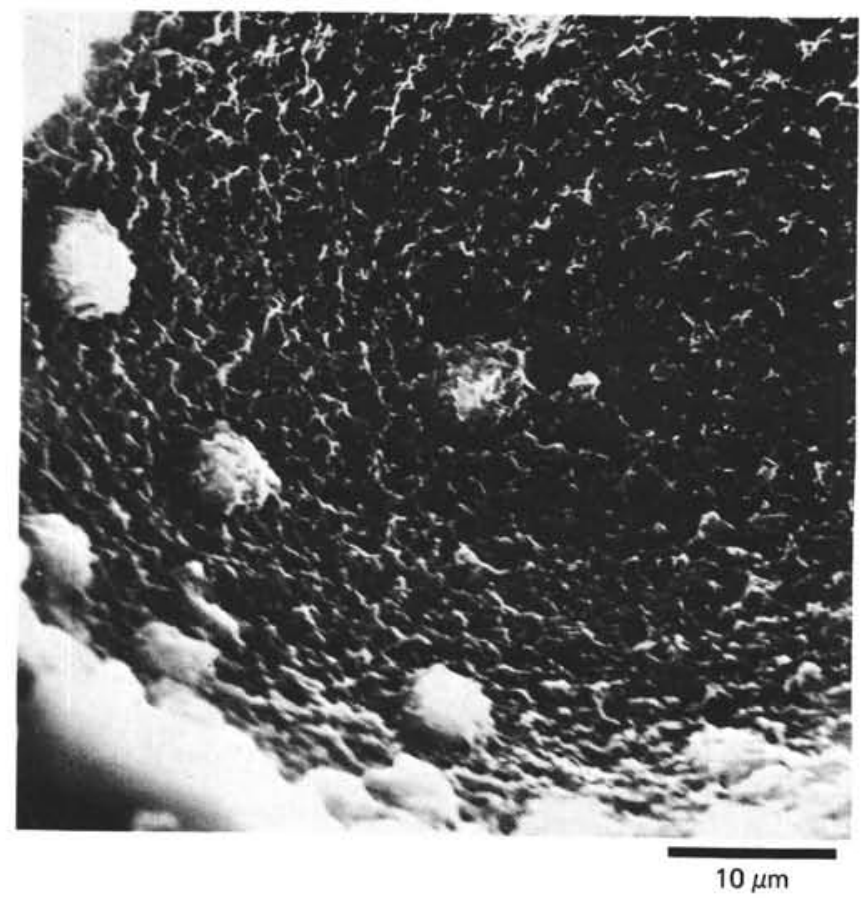

Figure 5. Porous surface texture ofvesicle wall and spherules as in Figure 4. SEM photo of Sample 15-1, 120-125 cm.

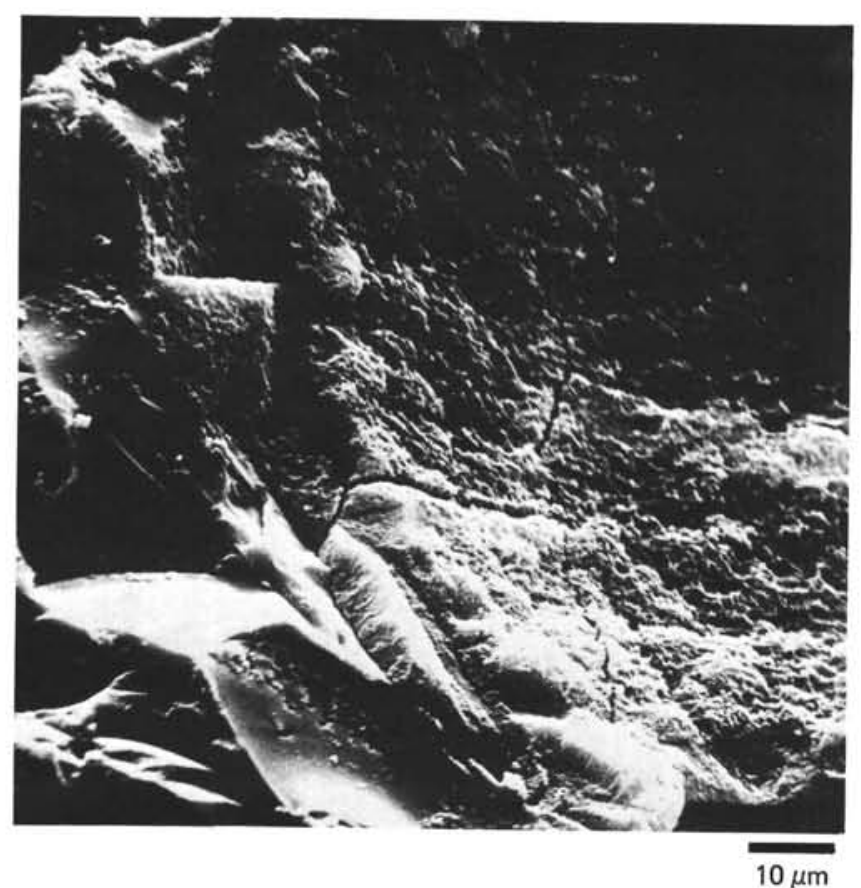

Figure 6. Vesicle with cracks in the wall surface and porous surface structure. SEM photo of Sample 15-1, 120-125 $\mathrm{cm}$.

\section{CHEMISTRY}

Partial analyses of three spherules from Sample 396-24-3, 77-82 cm (Table 1, columns 1 through 3 ) were made with a JEOL microprobe, using wavelengthdispersive spectrometers. The measurements were made against a natural sulfide standard and individual metals, using an excitation potential of $20 \mathrm{kV}$ and $16 \mathrm{nA}$ and a

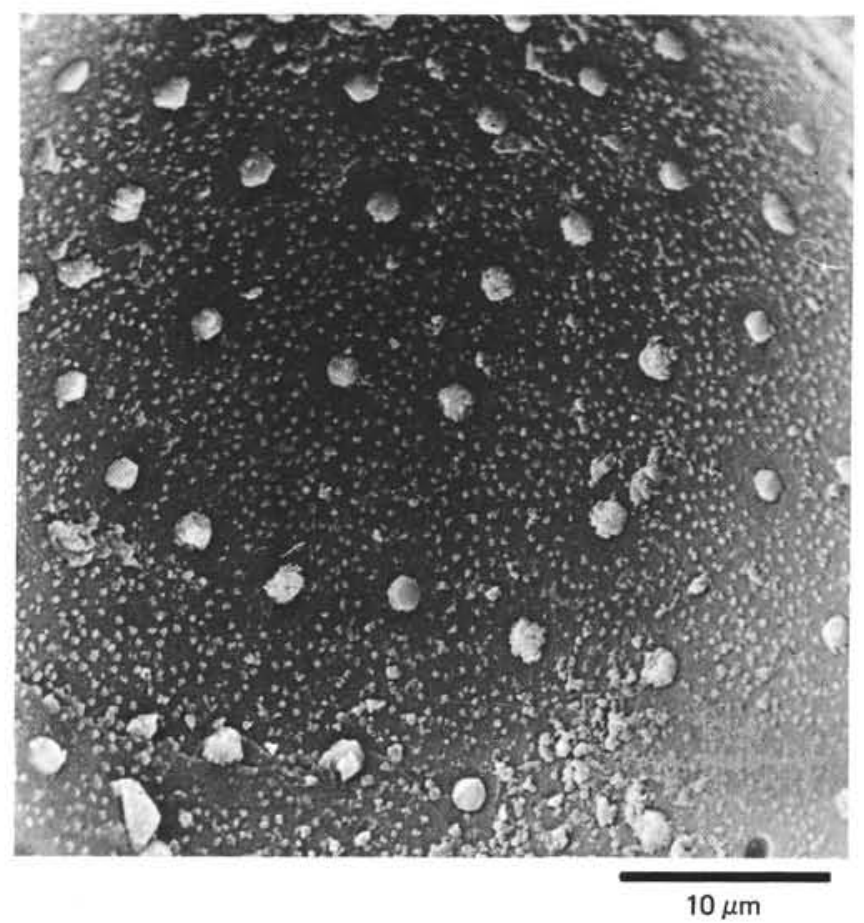

Figure 7. Part of a vesicle with two distinct populations of spherules. Halos around the larger spherules but not the smaller ones. SEM photo of Sample 15-1, 120-125 cm.

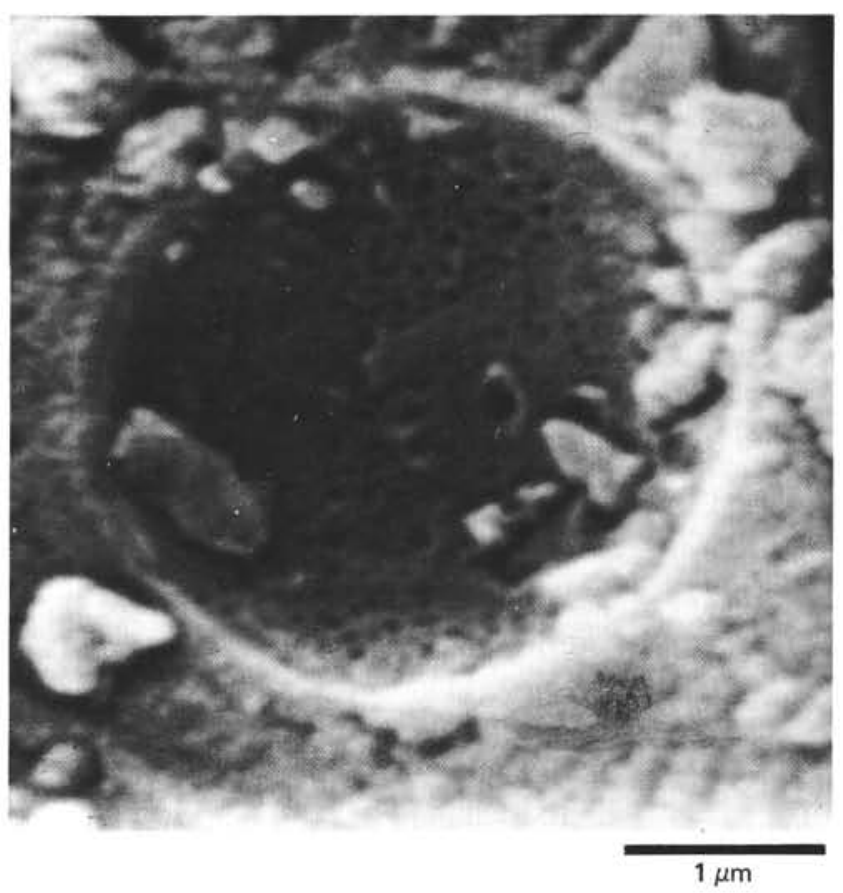

Figure 8. Hemispherical pit left by a broken-off spherule, dotted with numerous small pits $0.1 \mu \mathrm{m}$ in diameter. The rectangle in the center is a print of a microphenocryst. Other objects in the pit are dust. SEM photo of Sample $15-1,120-125 \mathrm{~cm}$.

measuring time of 20 seconds. The composition of the glass (Table 1, column 4) was determined by X-ray fluorescence analysis. The peak intensities for $\mathrm{Ni}$ and $\mathrm{Cu}$ were corrected for $\mathrm{Fe}$ and $\mathrm{Ti}$ interference. 


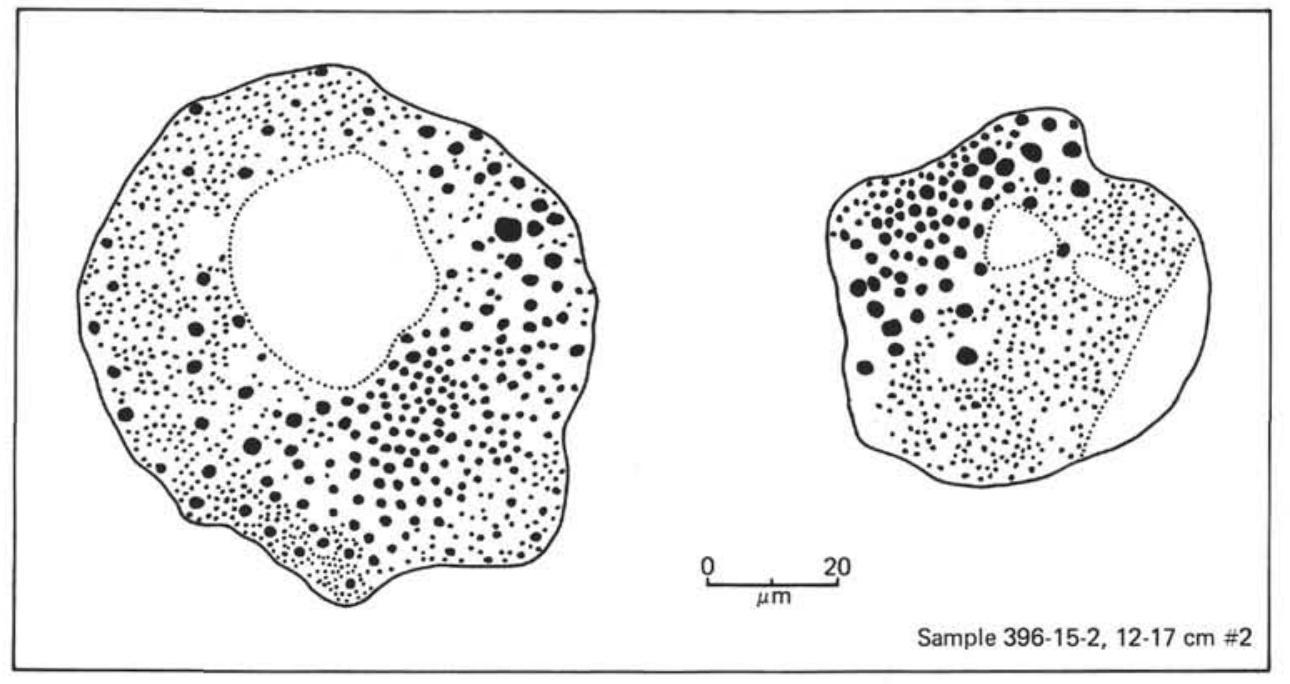

Figure 9. Sketches of two decorated vesicles as they appear in transmitted light. The two populations of spherules are not evenly distributed as in Figure 7. Note the spread of diameters among the large spherules. The blank areas delineated by small dots are missing in the thin section (left), or contaminated (right).

\section{DISCUSSION}

The discussion in this section is based on the assumption that the vesicles did not form long before quenching of the basaltic magma. Otherwise, the gas bubbles might have escaped from the melt. On the other hand, if they had formed at quenching, there should be some kind of correlation between vesicle size and distribution and the distance from the contact.

\section{Geometrical Relations}

The regular arrangement of the spherules in most of the vesicles suggests that they were formed from a gas phase. The close correlation between sizes and spacings of the spherules and their distances from pillow margins demonstrates that no sulfide was produced in the vesicles before quenching of the magma. This leads to the conclusion that sulfur, although dissolved in the silicate melt as sulfide (Katsura and Nagashima, 1974), exsolved as a gas (mainly $\mathrm{SO}_{2}$, Gerlach and Nordlie, 1975), which reacted to sulfide only after collection in vesicles. This is in contrast to sulfide globules which are also embedded in the glasses of this study. The conventional interpretation of such globules is that they were droplets of sulfide melt which immiscibly separated from the silicate melt without involvement of a gas phase.

The hemispherical pits left by broken-off spherules indicate that the spherules and the basaltic glass were in a liquid state at the time the sulfide was formed. The basaltic glass consolidated before the spherules crystallized. Otherwise, the pits would show casts of the sulfide crystals.

The increase of the spherule diameters and spacings with distance from pillow rims indicates that slower cooling of the basaltic magma promotes growth of larger spherules on a smaller number of nuclei. Differ- ences in slope of the regression lines in Figure 10 thus reflect different cooling rates.

The relative amount of sulfide, as expressed by the sulfide layer thickness, may be (Figure $10[\mathrm{~A}],[\mathrm{B}],[\mathrm{D}]$, and Moore and Calk, 1971 Figure 3), but is not always (Figure 10[c], [e]), greater in vesicles farther away from the contact. This may be a consequence of incomplete reaction of the gas with the basaltic melt, owing to rapid cooling. Accelerating forces (gravity?) acting on the magma were able to concentrate the spherules of one side of the vesicle, and this sometimes led to coalescence of spherules (Figures 4 and 9). This coalescence is another argument in favor of a formerly liquid condition of the sulfide. The arrangement of the smaller spherules in vesicles of this type indicates that they are, at least in part, younger than the larger spherules. Presumably, they formed at slightly lower temperatures on an increased number of condensation centers.

\section{Chemistry}

The compositions of the spherules correspond roughly to that of pyrrhotite (Table 1 ; see also data in Moore and Calk, 1971). The accuracy of the analyses is

TABLE 1

Compositions of Three Spherules (columns 1 through 3) and the Glassy Part (column 4) of Sample 396-24-3, 77-82 cm

\begin{tabular}{|c|c|c|c|c|c|c|c|}
\hline \multirow[b]{2}{*}{$\mathrm{Fe}$} & \multicolumn{2}{|c|}{1} & \multicolumn{2}{|c|}{2} & \multicolumn{2}{|c|}{3} & \multirow{2}{*}{$\begin{array}{c}4 \\
72200\end{array}$} \\
\hline & (19.18) & 48.3 & (23.82) & 52.4 & (21.46) & 50.2 & \\
\hline $\mathrm{Ni}$ & $(0.55)$ & 1.4 & $(0.52)$ & 1.2 & $(0.53)$ & 1.2 & 100 \\
\hline $\mathrm{Cu}$ & ( 2.45$)$ & 6.2 & ( 1.40 & 3.1 & ( 1.93$)$ & 4.5 & 58 \\
\hline $\mathrm{S}$ & (17.55) & 44.1 & (19.66) & 43.3 & (18.85) & 44.1 & n.d. \\
\hline Sum & (39.73) & 100.0 & $(45.40)$ & 100.0 & $(42.77)$ & 100.0 & \\
\hline
\end{tabular}

Note: Original data in parentheses, normalized figures without parentheses. Figures in columns 1 through 3 are in weight per cent, in column 4 in parts per million. 


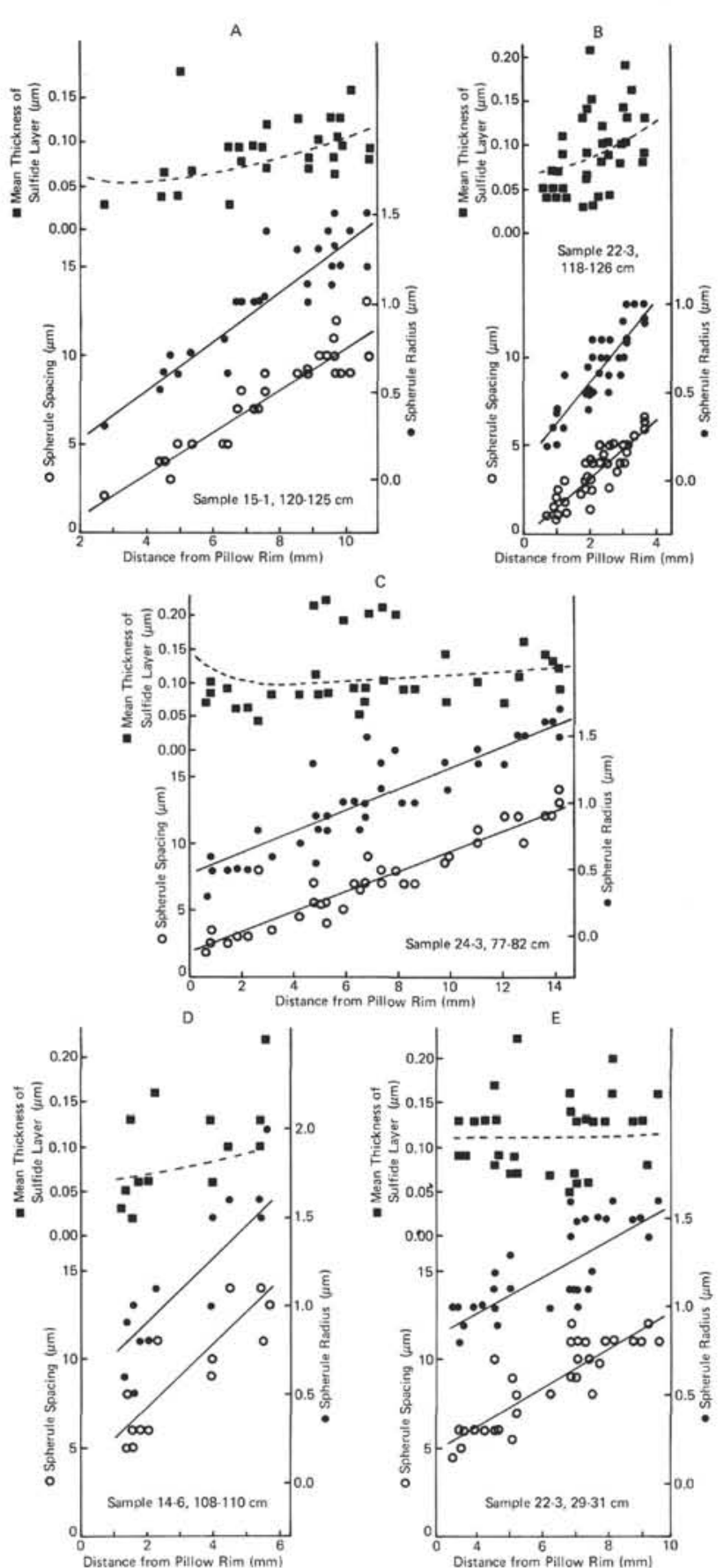

Figure 10. Plots of spacing between spherules (open circles), radii of spherules (solid circles), and calculated mean thicknesses of the sulfide layer in the vesicles (solid squares), versus distance from the contact. The first three values are given in micrometers, the last one in millimeters. Scales are marked with the symbols corresponding to the data points. The solid lines are regresion lines. Correlation coefficients for the upper and lower regression lines are (a) 0.94 and 0.94 , (b) 0.85 and 0.90 , (c) 0.91 and 0.94 , (d) 0.72 and 0.88 , (e) 0.79 and 0.87 . The broken line represents a theoretical thickness of the sulfide layer, as calculated from the regression lines. The uppermost squares in each figure are for large vesicles.

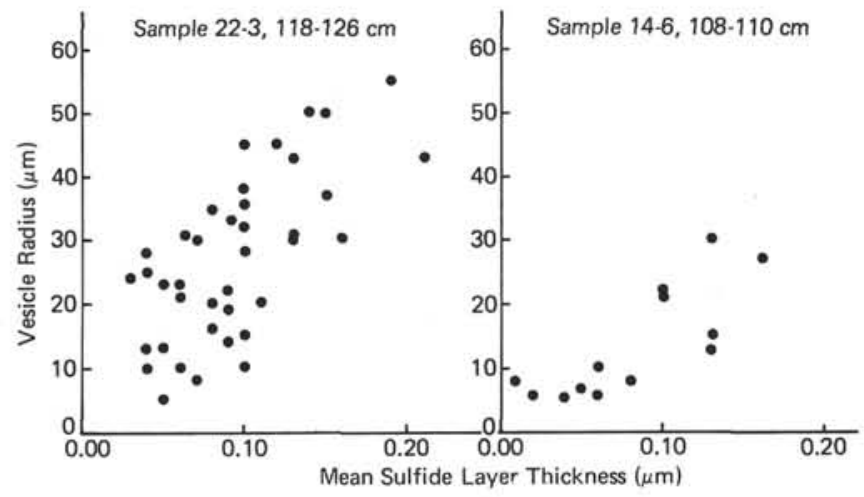

Figure 11. Plots of vesicle radii (vertical) versus mean sulfide layer thicknesses (horizontal) for samples of Figures $10, \mathrm{~b}$ and $\mathrm{d}$. The two plots represent both the steepest and flattest slopes of data scatter in the five samples of Figure 10 .

not adequate, however, for a rigorous discussion on the basis of the experimentally investigated Fe-Ni-S and Fe$\mathrm{Cu}-\mathrm{S}$ systems (Kullerud et al., 1969). All the same, some speculation is possible.

Pure pyrrhotite melts at $1192^{\circ} \mathrm{C}$. Small anıunts of nickel do not substantially lower this temperature, but copper (Craig and Naldrett, 1967), and oxygen (Naldrett, 1969) may lower it to about $1100^{\circ} \mathrm{C}$. This provides a narrow temperature interval within which the spherules may have been completely liquid.

In the whole rock, the relation of the elements is Fe : $\mathrm{Ni}: \mathrm{Cu}=722: 1: 0.6$. In the spherules it is $38.7: 1: 3.5$ (average of the three analyses of Table 1). This strong enrichment in $\mathrm{Ni}$ and $\mathrm{Cu}$, compared with $\mathrm{Fe}$, poses certain problems, in that it requires rapid and highly selective diffusion of $\mathrm{Ni}$ and $\mathrm{Cu}$ to the vesicle wall.

The amount of $\mathrm{Ni}$ and $\mathrm{Cu}$ in the vesicle can be calculated from the total amount and composition of sulfide in the vesicle. From this figure the volume of glass can be obtained, which would contain the same amount of $\mathrm{Ni}$ and $\mathrm{Cu}$. Under the assumption that all this $\mathrm{Ni}$ and $\mathrm{Cu}$ is delivered by complete depletion of a shell of glass around the vesicle, the calculation gives a thickness of that shell of $30 \mu \mathrm{m}$ for $\mathrm{Ni}$ and $100 \mu \mathrm{m}$ for $\mathrm{Cu}$ for large vesicles. The short time available for diffusion requires an enormous speed of diffusion. The time interval in which the temperature drops from $1160^{\circ} \mathrm{C}$ (temperature of the basaltic magma at its four-phase boundary olivine + clinopyroxene + plagioclase + melt, Tilley et al., 1964) to $1100^{\circ} \mathrm{C}$ (temperature of crystallization of the spherules) can be as short as 1 second. This represents a diffusion rate of up to 9 meters in one day.

Comparison with data from the literature (Moore and Calk, 1971; Mathez and Yeats, 1976) indicates that chemical equilibrium between silicate melt and spherules was not attained. The globules, which had sufficient time to equilibrate with the basaltic melt, show invariably higher $\mathrm{Ni}$ and $\mathrm{Cu}$ contents than the spherules. Obviously, more Fe was incorporated into the spherules than would correspond to equilibrium conditions. 


\section{Amount of Sulfur in the Vesicles}

The amount of sulfur present in the vesicles can be calculated in the same way as copper and nickel. It should be present in a reasonable proportion to the amount of gaseous sulfur that can be accommodated in the vesicles. Several assumptions have to be made for an estimate of the latter value.

1) The diameter of the vesicle was frozen in at about $900^{\circ} \mathrm{C}$.

2) In the 13 million years since extrusion of the basalt, the sea floor has sunk at least 1000 meters. Since the samples of this study have been drilled at a depth of 4650 meters, the basalt must have been extruded at a depth of about 3650 meters (about the present depth of the floor of the median rift at $23^{\circ} \mathrm{N}$ (Purdy and Rabinowitz, this volume).

3) Shrinkage of the vesicles caused by the reaction of sulfur in the gas phase in the formation of sulfides is neglected. Using these assumptions and the rather inaccurate figures for the thickness of the sulfide layer, the following calculation can be made: After decompression from about 350 bars to 1 bar and cooling from $900^{\circ} \mathrm{C}$ to $0^{\circ} \mathrm{C}$, the gas of a vesicle would have a volume 106 times greater than that of the vesicle. Taken as pure $\mathrm{SO}_{2}$, the gas content of a vesicle with a radius of $25 \mu \mathrm{m}$ would have a weight of $2 \times 10^{-8}$ grams, $10^{-8}$ grams of which would be sulfur. The amount of sulfide in such a vesicle typically is about $2.8 \times 10^{-9}$ grams of which are sulfur. That is, only 6 per cent of a gas with the density of $\mathrm{SO}_{2}$ has to be $\mathrm{SO}_{2}$ to deliver all the sulfur needed to form the sulfide spherules. This is of the same order of magnitude as in the calculated gas composition at $\mathrm{T}=$ $1000^{\circ} \mathrm{C}$ and $\mathrm{P}=100$ atm in Gerlach and Nordlie, 1974.

\section{ACKNOWLEDGMENTS}

S. Lee prepared the samples, assisted during microprobe analysis of the spherules, and improved the English of the manuscript. Dr. E. Mathez made valuable comments on an earlier version of the manuscript. Dr. R. Snethlage helped in discussing aspects of the ore petrology. Two scanning-electron microprobe photos were made by P. Eisenach, all others by Mrs. M. Werner, Institut für allgemeine and angewandte Geologie, München. The participation of Dr. E. Prosser, who provided the samples, on Leg 45 was funded by the Deutsche Forschungsgemeinschaft.

\section{REFERENCES}

Craig, J. R. and Naldrett, A. J., 1967. Minimum melting of nickeliferous pyrrhotite ores, Carnegie Inst. Wash. Yearbook, v. 66, p. 417-419.

Gerlach, T. M. and Nordlie, B. E., 1975. The C-O-H-S gaseous system, part III: Magmatic gases compatible with oxides and sulfides in basalic magmas, Am. J. Sci., v. 275 , p. $395-410$.

Katsura, T. and Nagashima, S., 1974. Solubility of sulfur in some magmas at 1 atmosphere, Geochim. Cosmochim. Acta, v. 38 , p. 517-531.

Kullerud, G., Yund, R. A., and Moh, G. H., 1969. Phase relations in the $\mathrm{Cu}-\mathrm{Fe}-\mathrm{S}, \mathrm{Cu}-\mathrm{Ni}-\mathrm{S}$, and $\mathrm{Fe}-\mathrm{Ni}-\mathrm{S}$ systems, Econ. Geol. Monogr. 4, p. 323-343.

Mathez, E. A. and Yeats, R. S., 1976. Magmatic sulfides in basalt glass from DSDP Hole 319A and Site 320, Nazca plate. In Yeats, R. S., Hart, S. R., et al., Initial Reports of the Deep Sea Drilling Project, v. 24: Washington (U.S. Government Printing Office), p. 363-373.

Moore, J. G. and Calk, L., 1971. Sulfide spherules in vesicles of dredged pillow basalt, $A m$. Mineralogist, v. 56, p. 476-488.

Moore, J. G. and Schilling, J.-G., 1973. Vesicles, water, and sulfur in Reykjanes ridge basalts, Contrib. Mineral. Petrol., v. 41 , p. $105-118$.

Naldrett, A. J., 1969. A portion of the system Fe-S-O between $900^{\circ}$ and $1080^{\circ} \mathrm{C}$ and its application to sulfide ore magmas, J. Petrol., v. 10, p. 171-201.

Tilley, C. E., Yoder, H. S., Jr., and Schairer, J. F., 1964. New relations on melting of basalts, Carnegie Inst. Wash. Yearbook, v. 63, p. 92-97.

Yeats, R. S. and Mathez, E. A., 1976. Decorated vesicles in deep-sea basalt glass, Eastern Pacific, J. Geophys. Res., v. 81 , p. $4277-4284$. 